\title{
Analisis Perbandingan Kualitas Layanan Sistem Antara Protokol HTTP dan MQTT Pada Monitoring Kelembaban Tanah
}

\author{
Anang Dwi Prakoso \\ Program Studi Teknik Elektro \\ Telekomunikasi Fakultas \\ Teknik Telekomunikasi dan \\ Institut Teknologi Telkom \\ Purwokerto, Indonesia \\ 18101216@ittelkompwt.ac.id
}

\author{
Fikra Titan Syifa \\ Program Studi Teknik Elektro \\ Telekomunikasi Fakultas \\ Teknik Telekomunikasi dan \\ Institut Teknologi Telkom \\ Purwokerto, Indonesia \\ fikratitan@ittelkompwt.ac.id
}

\author{
Danny Kurnianto \\ Program Studi Teknik Elektro \\ Telekomunikasi Fakultas \\ Teknik Telekomunikasi dan \\ Institut Teknologi Telkom \\ Purwokerto, Indonesia
}

\begin{abstract}
This paper discusses the comparison of service quality between HTTP protocol and MQTT protocol implemented using internet of things to research on soil moisture around plants, quality of service compared to delay, jitter, throughput and packet loss. In this study the results showed that the HTTP and MQTT protocols have an average delay value below 150 or $63 \mathrm{~ms}$. HTTP has an average jitter value between 0 - $62 \mathrm{~ms}$, while MQTT has a jitter range value of between $0-16 \mathrm{~ms}$. Whereas the HTTP throughput value is $88 \mathrm{~ms}$ and the MQTT protocol is 68 ms. Then for packet loss parameters both have the same quality as it generates a packet loss value of $0 \%$. In this study it can be concluded that the use of http protocols is the superior protocol of MQTT in terms of quality of service.
\end{abstract}

Keyword-Soil Moisture, HTTP, MQTT, Quality of Service

\section{PENDAHULUAN}

Tanaman merupakan tumbuhan yang dibudidayakan agar dapat diambil manfaatnya. Budidaya tanaman sendiri pada dasarnya dapat menjadi peluang usaha yang menjanjikan. Mulai dari budidaya tanaman hias, sayur mayur dan lain sebagainya. Penyiraman tanaman secara manual dapat mengganggu efisiensi waktu dan tenaga. Pada penyiraman tanaman secara manual juga sering kali memerlukan perhatian yang lebih sehingga penyiraman terkadang tidak dilakukan dengan baik karena faktor lalai dari manusia, dan mengakibatkan tanaman tidak dapat tumbuh dengan baik karena kekurangan air[1].

Perkembangan teknologi sangat pesat dan sangat mempengaruhi kehidupan, sehingga banyak orang yang mengembangkan sistem monitoring atau perawatan tanaman menggunakan teknologi sekarang demi mendapatkan hasil yang maksimal. Banyak dari mereka yang telah mengembangkan teknologi untuk dapat meringankan beban petani dengan memanfaatkan teknologi seperti IoT. Adapun kemampuan pada IoT seperti berbagi data, remote control, dan sebagainya. Oleh karena itu perkembangan tekhnologi IoT saat ini dapat merambah merambah ke setiap bidang kehidupan. Pemanfaatan teknologi modern pada bidang pertanian diharapkan dapat meningkatkan hasil pertanian terutama budidaya tanaman. [1].

Beragam penelitian terkain IoT telah dikambangkan diantaranya Alat penyiram otomatis dengan sensor kelembaban tanah berbasis atmega 328 [3]. Perancangan alat penyiram tanaman otomatis berbasis sensor dan mikrokontroler [4]. Analisis penggunaan HTTP yang digunakan dalam menyelesaiakan masalah jaringan komunikasi restfull web service. Namun dalam penggunaan protokol HTTP dan MQTT keberhasilan dalam menyampaikan sebuah informasi dari pengirim (client) kepada penerima (server) merupakan salah satu hal yang penting. Penyebab kesalahan dalam kurang baiknya kulitas layanan yang diperoleh diantaranya karena paket yang hilang atau kurang saat informasi dikirimkan. Berdasarkan kajian pustaka, maka penulis melakukan penelitian tentang kualitas layanan terhadap perangkat monitoring kelembaban tanah berbasis protocol HTTP da MQTT. Penelitian ini bertujuan untuk mengetahui perbandingan kualitas layanan pada protokol HTTP dan MQTT terhadap perangkat sensor kelembaban tanah sebagai media implementasinya untuk melakukan peneliti.

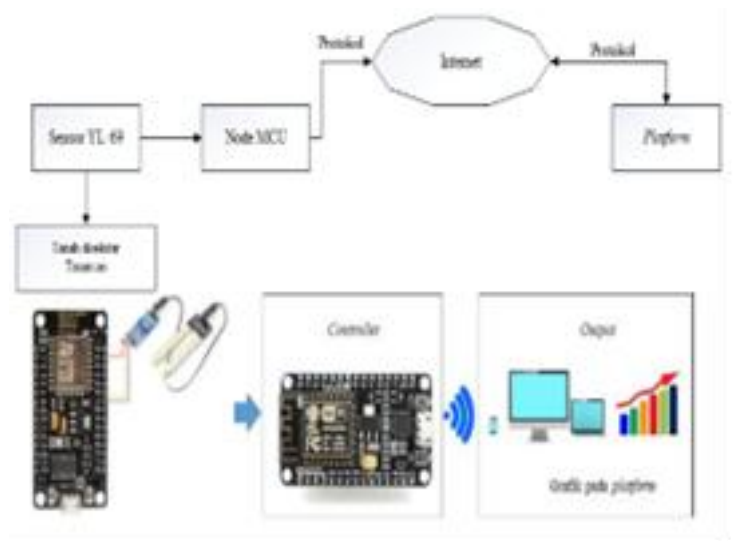

Gambar 1. Arsitektur Sistem 


\section{METODE PENELITIAN}

Pada penelitian ini penulis mengimplementasikan jaringan yang akan digunakan untuk sebuah perangkat monitoring kelembapan tanah. Pada gambar arsitektur sistem diatas dapat dijelaskan bahwa pada perancangan alat ini dimulai dengan menaruh sensor YL-69 pada tanah. Kemudian sensor YL-69 akan mendeteksi tingkat kelembaban tanah, lalu data nilai kelembaban tanah akan dikirim ke node MCU. Dari node MCU data kelembaban akan dikirim ke sebuah platform. Sementara itu, protokol komunikasi yang digunakan sebagai pengiriman data adalah HTTP dan MQTT. Kemudian data kelembaban tanah akan ditampilkan pada sebuah platform penyedia layanan IoT. Pada gambar diatas juga terdapat ilustrasi proses data perencanaan sistem.

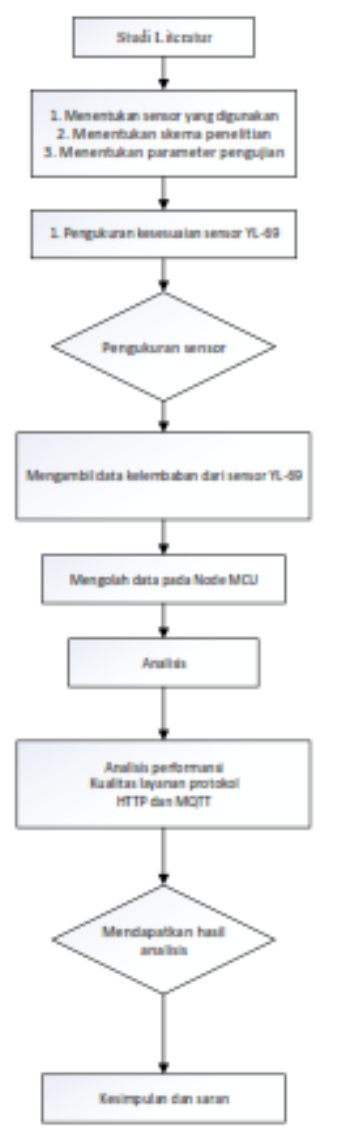

Gambar 2. Flowchart Alur Penelitian

Dimana dari gambar diatas dapat dilihat bahawa input dari penelitin ini adalah sensor YL-69. Setelah sensor ini membaca tingkat kelembaban tanah, selanjutnya data akan diproses oleh Node MCU. Node MCU disini berperan sebagai controller, yang selanjutnya data kelembaban tanah akan dikirim ke platform dengan via WiFi. Data pada platform akan ditampilkan dalam bentuk grafik yang merupakan output dari penelitian ini.

Pada intinya alat ini bekerja dengan cara mengambil sebuah data dari sensor yang ada pada alat tersebut. Setelah itu data akan dikirimkan melalui node MCU dengan menggunakan jaringan internet yang nantinya akan terhubung pada platform. Berikut beberapa penjelasan komponen yang ada pada Blok Diagram diatas :

a. YL-69 berfungsi sebagai alat sensor/pendeteksi kelembaban tanah yang ada pada tanah disekitar tanaman.

b. Node MCU sebagai pengolah data yang akan ditampilkan keluarannya pada sebuah platform.

c. Pengriman data dari Node MCU ke platform adalah via internet dengan menggunkan WiFi.

d. Protokol komunikasi yang digunakan pada saat pengiriman data adalah protokol HTTP dan MQTT.

e. Platform berfungsi untuk menampilkan keluaran hasil kelembaban tanah yang didapatkan.

Pengujian terbagi menjadi empat skenario pengujian, yaitu pengujian pada protokol HTTP siang malam dan protokol MQTT siang dan malam, masing - masing pengujian menguji coba kulitas layanan pada keempat kategori parameter dari delay, jitter, throughput dan packet loss. Pengujian dilakukan di tanah disekitar tanaman cabai dikawasan Baturaden dengan masing - masing pengujian dilakukan selama 1 menit lamanya untuk mengetahui hasil dari kualitas layanan.

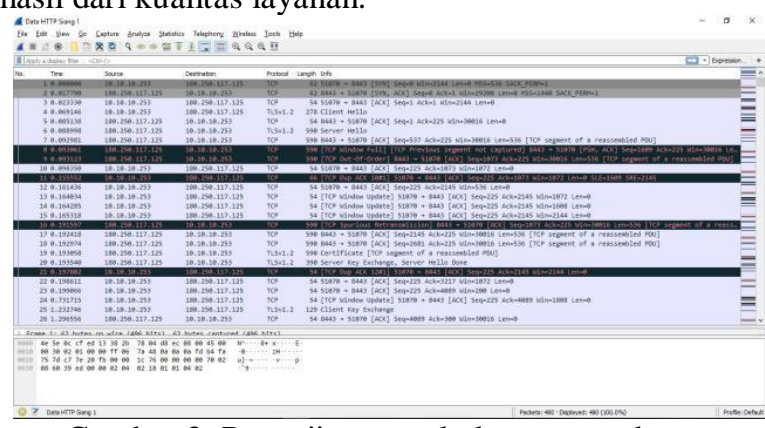

Gambar 3. Pengujian protokol menggunakan Wireshark

Pengujian dilakukan selama satu menit dan dalam dua waktu yang berbeda yaitu siang dan malam. Pada percobaan pertama yaitu HTTP siang dan MQTT malam. Pengujian awal menguji parameter dari delay. Delay merupakan waktu tunda pada suatu paket yang terjadi akibat adanya proses transmisi dari suatu titik awal ke titik lain yang menjadi tujuannya. Rumus perhitungan delay yaitu :

$$
\text { Rata }- \text { rata Delay }=\frac{\text { Total Delay }}{\text { Total paket yang diterima }}
$$

Tabel 1. Indeks Kategori Nilai Delay

\begin{tabular}{|c|r|c|}
\hline Kategori & Besar Delay & Indeks \\
\hline Sangat Bagus & $<150 \mathrm{~ms}$ & 4 \\
\hline Bagus & $150-300 \mathrm{~ms}$ & 3 \\
\hline Sedang & $300-450 \mathrm{~ms}$ & 2 \\
\hline Jelek & $>450 \mathrm{~ms}$ & 1 \\
\hline
\end{tabular}


Pengujian selanjutnya menguji parameter dari jitter. Jitter atau variasi delay menunjukan banyaknya variasi delay pada transmisi data di jaringan. Nilai jitter dapat dipengaruhi oleh adanya antrian trafik, dipengaruhi juga oleh besarnya tabrakan antar paket yang terjadi pada jaringan IP, waktu pengolahan data, dan waktu penghimpunan ulang paket- paket di akhir perjalanan jitter.

$$
\text { Jitter }=\frac{\text { Total Delay }}{\text { Total paket yang diterima }-1}
$$

Tabel 2. Indeks Kategori Nilai Jitter

\begin{tabular}{|c|c|c|}
\hline Kategori & Besar Jitter & Indeks \\
\hline Sangat Bagus & $0 \mathrm{~ms}$ & 4 \\
\hline Bagus & $0-75 \mathrm{~ms}$ & 3 \\
\hline Sedang & $75-125 \mathrm{~ms}$ & 2 \\
\hline Jelek & $125-225 \mathrm{~ms}$ & 1 \\
\hline
\end{tabular}

Pengujian selanjutnya menguji parameter dari throughput. Throughput merupakan jumlah kedatangan paket yang dapat teramati pada tujuan selama interval waktu tertentu dibagi oleh durasi interval waktu tersebut. Throughput juga merupakan transfer data efektif yang diukur oleh bps dalam melakukan pengiriman data.

$$
\text { Throughput }=\frac{\text { (Jumlah data yang dikirim) }}{\text { Waktu pengiriman data }}
$$

Pengujian terakhir untuk mengetahui nilai parameter dari packet los. Packet loss menggambarkan kegagalan transmisi total paket dalam mencapai tujuannya. Kegagalan tersebut dapat disebabkan oleh beberapa kemungkinan

Data yang dikirim - paket data yang diterima

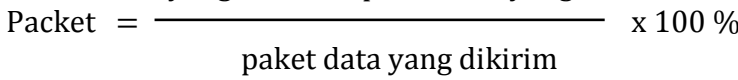

Tabel 4. Indeks Kategori Nilai Packet Loss

\begin{tabular}{|c|c|c|}
\hline Kategori & Packet Loss & Indeks \\
\hline Sangat Bagus & $0 \%$ & 4 \\
\hline Bagus & $3 \%$ & 3 \\
\hline Sedang & $15 \%$ & 2 \\
\hline Jelek & $25 \%$ & 1 \\
\hline
\end{tabular}

\section{HASIL DAN PEMBAHASAN}

\section{Pengujian Delay pada HTTP dan MQTT}

Hasil rata-rata delay yang menghasilkan pada parameter waktu diatas bahwa pengiriman paket pada data delay memiliki nilai tertinggi yaitu sebesar 68 ms pada waktu siang hari dengan protocol HTTP, sementara pada nilai terendah pada HTTP malam hari dengan rata-rata menunjukan delay sebesar $58 \mathrm{~ms}$. Hasil rata-rata delay yang didapatkan menggunakan protokol HTTP dan MQTT ini jika dibandingkan dengan standar THIPON (table 1) nilai yang dihasilkan adalah sangat memuaskan. Karena hasil rata-rata delay adalah kurang dari $150 \mathrm{~ms}$, dan jika dibandingkan dengan standarisasi THIPON, hasil kualitas layanan yang dihasilkan oleh protokol HTTP dan MQTT adalah sangan baik karena seluruh nilai rata-rata delay dibawah $150 \mathrm{~ms}$ dan dikategorikan sangat baik. Namun jika dilihat dari nilai delay, antara protocol HTTP dan MQTT, protokol HTTP lebih unggul karena memiliki nilai delay yang lebih rendah dibandingkan MQTT. Sehingga dapat disimpulkan bahwa dari parameter delay, HTTP lebih unggul dibadingkan MQTT.

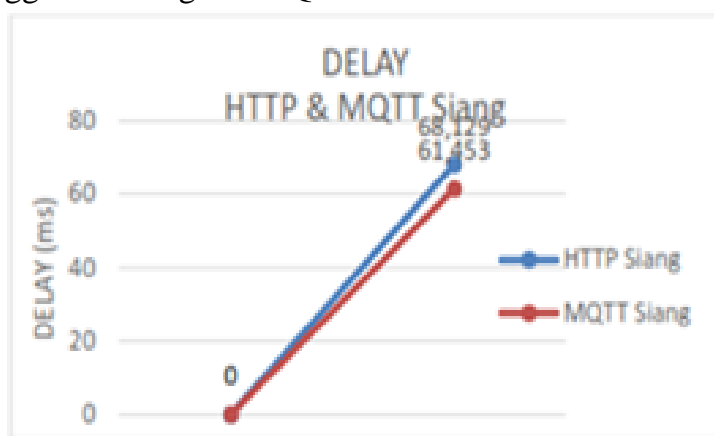

Gambar 4. Nilai Delay pada HTTP dan MQTT Siang

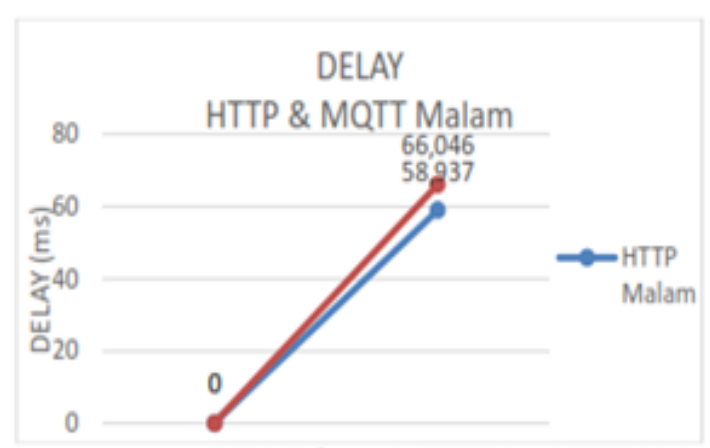

Gambar 5. Nilai Delay pada HTTP dan MQTT Malam

\section{Pengujian Jitter pada HTTP dan MQTT}

Dari grafik 6 dan 7 menunjukan bahwa delay yang dihasilkan protokol HTTP dan MQTT adalah sedang. Karena nilai jitter yang dihasilkan tidak ada nilai yang lebih dari $225 \mathrm{~ms}$. Pada grafik tersebut juga terlihat bahwa jitter dengan menggunakan protokol HTTP dan MQTT mengalami kenaikan disetiap percobaan dilakukan pada malam hari, hal ini dikarenakan pada malam hari data yang dikirimkan lebih banyak karena sensor kelembaban mendeteksi tingkat data yang lebih besar dibandingkan siang, karena pada malam hari suhu tanah lebih lembab dari malam sehingga membuat data yang dikirimkan lebih banyak. Dari hasil grafik total perhitungan jitter seperti yang telah dijelaskan sebelumnya, selanjutnya hasil data total rata-rata jitter akan dibandingkan dengan standar THIPON. Dapat dilihat table standar THIPON adalah pada (tabel 2). 


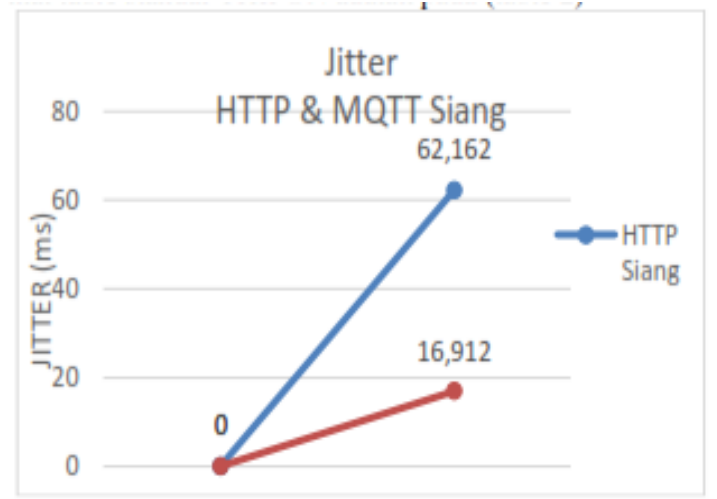

Gambar 6. Nilai Jitter pada HTTP dan MQTT Siang

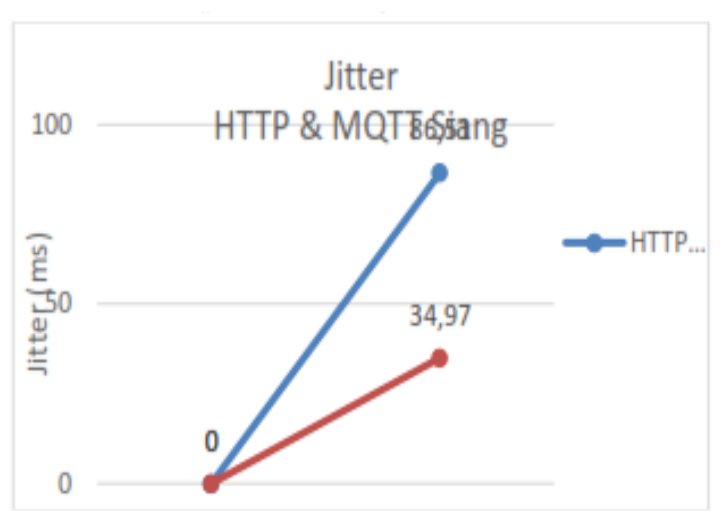

Gambar 7. Nilai Jitter pada HTTP dan MQTT Malam

\section{Pengujian Throughput pada HTTP dan MQTT}

Dari grafik 8 dan 9 dapat disimpulkan bahwa pengambilan data dilihat dari waktu pengambilan datanya, akan sangat berpengaruh terhadap nilai kualitas layanan. Dapat dilihat bahwa rata-rata throughput, lebih tinggi dari pada delay, karena pada dasarnya throughput dan delay adalah parameter yang berbanding terbalik. Semakin tinggi throughput, maka akan semakin rendah delay yang dihasilkan maka kualitasnya baik, jika semakin rendah nilai throughput, maka semakin tinggi nilai delay yang dihasilkan untuk menunjukan kualitas layanannya kurang baik.

Namun dilihat dari standarisasi THIPON, hasil throughput yang dihasilkan adalah baik karena ratarata nilai throughput adalah diatas 75 bps. Table standarisasi THIPON dapat dilihat pada (table 3). Dapat dilihat bahwa grafik pengambilan data dengan nilai throughput tertinggi adalah pada saat malam hari yaitu sebesar 88 bps. Dari hasil total throughput diatas, HTTP memiliki kategori throughput yang baik karena memiliki nilai rata-rata diatas 75 bps. Adapun standar THIPON untuk menentukan kategori throughput dapat dilihat pada table 2.5. Jadi kesimpulanya kualitas throughput dari kedua protokol adalah HTTP yang memiliki kualitas yang lebih baik dari pada MQTT.

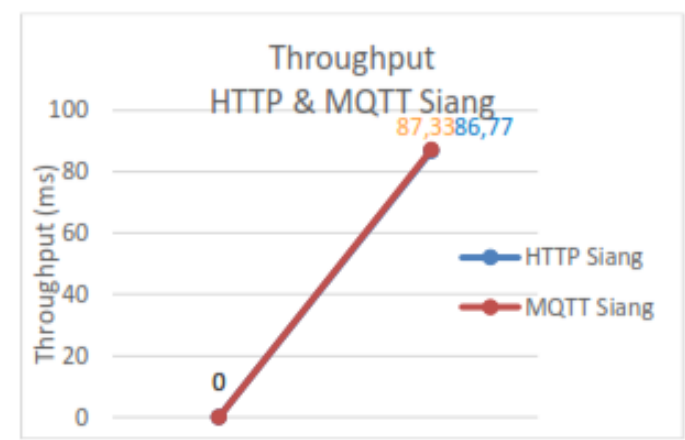

Gambar 8. Throughput pada HTTP dan MQTT Siang

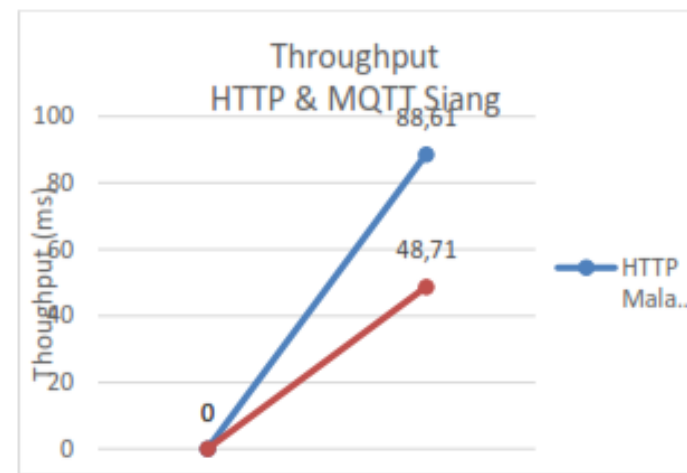

Gambar 9. Throughput pada HTTP dan MQTT Malam

\section{Pengujian Packet Loss HTTP dan MQTT}

Pada gambar dibawah menunjukan bahwa tidak adanya paket yang hilang. Padahal sebelumnya pada pengujian throughput, jitter dan delay tiap pengujian terus mengalami kenaikan dan penurunan kualitas jaringan, namun pada tiap pengujian tersebut tidak terdapat packet loss atau pengiriman paket yang hilang. Hal ini disebabkan dalam pengiriman data adalah karena tidak adanya timbal balik data ACK dari platform ke wireshark, sehingga data yang dihasilkan adalah 0\%. Selain itu packet loss juga biasanya terjadi pada pengiriman data dengan ukuran data yang besar, hal ini pun hanya akan mengurangi ukuran paket bukan adanya kehilangan paket.

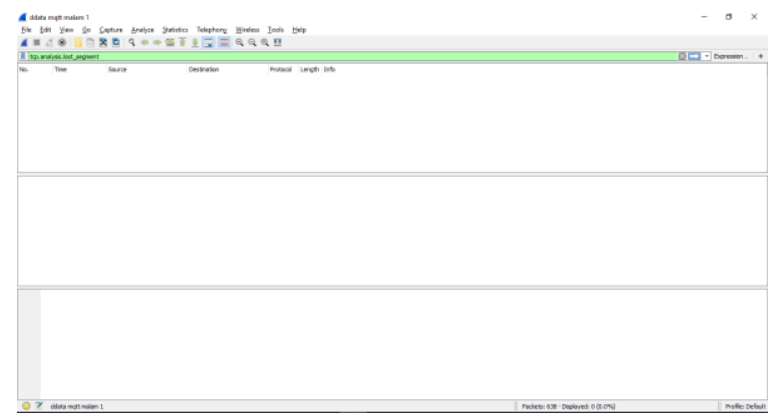

Gambar 10. Tidak adanya paket yang hilang. 
Dapat disimpulkan dari dalam pengiriman data tidak terdapat gangguan yang mengakibatkan hilangnya paket yang dikirim sehingga nilai packet loss bernilai $0 \%$. Dari hasil grafik tersebut, dapat dibandingkan bahwa kedua protokol memiliki nilai packet loss yang sama yaitu $0 \%$, sehingga kategori packet loss dilihat dari standar THIPON, keduanya memiliki indikasi Sangat Baik. Dapat disimpulkan pada kategori packet loss, kedua protokol memiliki performansi kualitas layanan yang sama baiknya. Adapun bentuk grafik dari hasil packet loss antara HTTP dan MQTT adalah sebagai berikut :

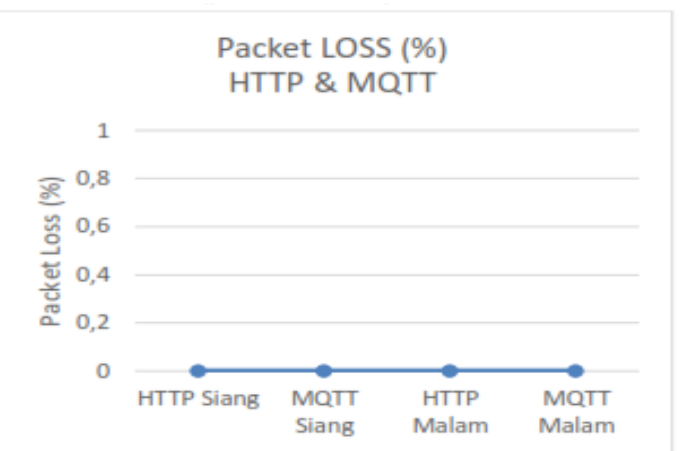

Gambar 11. Packet Loss pada HTTP dan MQTT

\section{KESIMPULAN}

Berdasarkan pembahasan mengenai analisis kualitas layanan system monitoring kelembaban tanah dengnan menggunakan protokol HTTP dan MQTT, maka dapat diperoleh beberapa kesimpula dari delay hasil yang didapatkan sangat baik karena nilai delai masih dibawah $150 \mathrm{~ms}$, pada layanan jitter kualitas yang diperoleh baik karena masih dalam rentang 75 $125 \mathrm{~ms}$. Pada kualitas throughput kualitas yang didapat baik karena masih dalam rentang $75-100$ msa dan pada kualitas packet loss yang diperoleh sangat baik karena tidak ada paket yang hilang.

\section{UCAPAN TERIMAKASIH}

Penulis berterima kasih kepada IT Telkom Purwokerto seluruh Civitas yang terkait atas dukungan moril maupun material dalam pelaksanaan penelitian dan publikasi ini.

\section{DAFTAR PUSTAKA}

[1] D. Kurniawan, Yaddarabullah, and G. Suprayitno, "Implementasi Internet of Things pada Sistem Irigasi Tetes dalam Membantu Pemanfaatan Urban Farming," 7 th Univ. Res. Colloq., no. June, pp. 106-117, 2018.

[2] M. F. Faizi, "Gambar 1.1 Board NodeMcu 3," pp. 3-9, 2017.

[3] A. Bachri and E. W. Utomo, "Prototype Penyiram Tanaman Otomatis Dengan Sensor Kelembaban Tanah Berbasis Atmega 328," J. Elektro, vol. 2, no. 1, pp. 5-10, 2017, doi: 10.30736/je.v2i1.33.

[4] J. M. S. Waworundeng, N. Chandra Suseno, R. Ricky, and Y. Manaha, "Seminar Nasional
Multi Disiplin Ilmu Perancangan Alat Penyiram Tanaman Otomatis berbasis Sensor dan Mikrokontroler," no. November, pp. 241-247, 2017.

[5] O. B. Pratama, A. Bhawiyuga, and K. Amron, "Pengembangan Perangkat Lunak IoT Cloud Platform Berbasis Protokol Komunikasi HTTP," J. Pengemb. Teknol. Inf. dan Ilmu Komput. Univ. Brawijaya, vol. 2,no. 9, 2018.

[6] P. Lahan, "Peluang Usaha Budidaya Cabai? Daftar Isi Buku 01."

[7] U. P. T. Sumber et al., "Perbedaan Http dan Https," pp.11-13, 2017.

[8] G. Y. Saputra, A. D. Afrizal, F. K. R. Mahfud, F. A.Pribadi, and F. J. Pamungkas, "Penerapan Protokol MQTT Pada Teknologi Wan (Studi Kasus Sistem Parkir Univeristas Brawijaya)," Inform. Mulawarman J. Ilm. Ilmu Komput., vol. 12, no. 2, p. 69, 2017, doi:10.30872/jim.v12i2.653.

[9] R. Wulandari, “Analisis Qos (Quality Of Service) Pada Jaringan Internet (Studi Kasus : Upt Loka Uji Teknik Penambangan Jampang Kulon - Lipi)," J.Tek. Inform. dan Sist. Inf., vol. 2, no. 2, pp. 162172,2016, doi: 10.28932/jutisi.v2i2.454

[10] I. T. Percobaan, "Analisa Jaringan Menggunakan WireShark."

[11] D. T. Andariesta, M. Fadhlika, A. Rajak, N. Siti, and M. Djamal, "Sistem Irigasi Sederhana Menggunakan Sensor Kelembaban untuk Otomatisasi dan Optimalisasi Pengairan Lahan," no. July 2016, pp. 89-93, 2015.

[12] Alawiah, AmeliaRafi Al Tahtawi, Adnan (2018) Sistem Kendali dan Pemantauan Ketinggian Air pada Tangki Berbasis Sensor Ultrasonik

[13] Ulumuddin, USudrajat, MRachmildha, T DIsmail, NHamidi, E A Z (2017) Prototipe Sistem Monitoring Air Pada Tangki Berbasis Internet of Things Menggunakan Nodemcu Esp8266 Sensor dan Ultrasonik

[14] Heru Susanto, Agus Nurcahyo (2018) Desain Dan Implementasi Sistem Monitoring Tegangan Dan Arus Motor Induksi Tiga Phase Menggunakan Konsep Internet Of Things (IOT)

[15[ Samuel Siregar dan Muhammad Rivai (2019) Monitoring dan Kontrol Sistem Penyemprotan Air Untuk Budidaya Aeroponik Menggunakan NodeMCU ESP8266

Copyright @2016 PROtek : Jurnal Ilmiah Teknik Elektro (c) (†) (-) lisensi Creative Commons Attribution 4.0 International License 